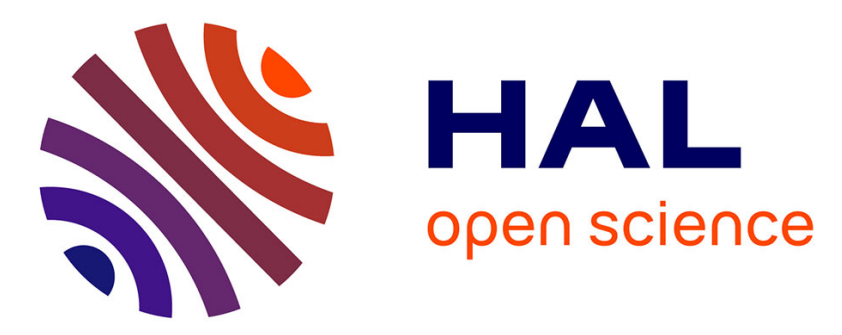

\title{
A highly selective synthesis of $\alpha$-monofluoro- and $\alpha$-monochloro- benzylphosphonates using electrophilic halogenation of benzylphosphonates carbanions
}

\author{
Bogdan Iorga, Frédéric Eymery, Philippe Savignac
}

\section{To cite this version:}

Bogdan Iorga, Frédéric Eymery, Philippe Savignac. A highly selective synthesis of $\alpha$-monofluoroand $\alpha$-monochloro- benzylphosphonates using electrophilic halogenation of benzylphosphonates carbanions. Tetrahedron Letters, 1998, 39 (22), pp.3693-3696. 10.1016/s0040-4039(98)00648-0 . hal03161382

\section{HAL Id: hal-03161382 \\ https://hal.science/hal-03161382}

Submitted on 10 Mar 2021

HAL is a multi-disciplinary open access archive for the deposit and dissemination of scientific research documents, whether they are published or not. The documents may come from teaching and research institutions in France or abroad, or from public or private research centers.
L'archive ouverte pluridisciplinaire HAL, est destinée au dépôt et à la diffusion de documents scientifiques de niveau recherche, publiés ou non, émanant des établissements d'enseignement et de recherche français ou étrangers, des laboratoires publics ou privés. 


\title{
A Highly Selective Synthesis of $\alpha$-Monofluoro- and $\alpha$-Monochloro- benzylphosphonates Using Electrophilic Halogenation of Benzylphosphonates Carbanions
}

\author{
Bogdan Iorga, Frédéric Eymery and Philippe Savignac \\ Laboratoire Hétéroéléments et Coordination, DCPH, CNRS et Ecole Polytechnique \\ 91128 Palaiseau Cedex, France.*
}

\begin{abstract}
The selective electrophilic monofluorination and monochlorination of a wide variety of diethyl benzylphosphonates have been realized in a one-pot procedure. The monohalogenation was accomplished by intermediate of a benzylic carbanion protected with TMSCl using $\mathrm{N}$-fluorobenzenesulfonimide (NFBS) and hexachloroethane, respectively. After mild removal of protecting group, this procedure delivers the $\alpha$-monohalogenobenzylphosphonates in high yields $(68-97 \%)$ and pure form.
\end{abstract}

The $\alpha$-monofluoro- and $\alpha$-monochlorophosphonates are recognized as important and useful compounds for independent reasons. The first ones behave as phosphate mimics for biological systems. ${ }^{1}$ Due to the fluorine electronegativity, the monofluorophosphonate function has a $\mathrm{pKa}$ almost identical to that of the corresponding phosphates. These analogues could be complexed similarly to the natural ligands but could not be hydrolyzed. ${ }^{2}$ By contrast, the monochlorophosphonates are widely utilized synthetic reagents and especially as ideal precursors for the generation of symmetrical or unsymmetrical acetylenic compounds in mild conditions by the Wittig-Horner reaction. ${ }^{3}$

The preparation of monohalogenophosphonates by selective electrophilic halogenation at the $\alpha-\mathrm{CH}_{2}$ position by carbanionic way is a delicate and difficult to control process. This reaction generates unavoidably a monohalogenated derivative more acidic than the initial phosphonate, thus inducing an acid-base equilibrium which evolves toward the formation of a mixture of mono- and dihalogenophosphonates. ${ }^{4}$ This methodology has been succesfully exploited lately to prepare the $\alpha, \alpha$-difluorinated phosphonates ${ }^{5 a-c}$ or to introduce fluorine on a tertiary carbon. ${ }^{6}$ The $\alpha, \alpha$-difluorinated phosphonates can also be obtained by a $\mathrm{CuCl}$ promoted coupling reaction between aryl iodides and difluoromethylcadmium reagents. $5 \mathrm{~d}$

We report here a highly selective and attractive one-pot procedure for the synthesis of diethyl $\alpha$-monofluoro- 5 and $\alpha$-monochloro- $\mathbf{6}$ benzylphosphonates from diethyl benzylphosphonates $\mathbf{1}$, based on the electrophilic halogenation of a benzylic carbanion transiently protected by a trimethylsilyl group. The starting

*Fax. (+33) 01693339 90.E-mail : dcph@poly.polytechnique.fr 
materials $\mathbf{1}$ are commercially available or prepared on laboratory scale by the Michaelis-Arbuzov reaction between triethyl phosphite and corresponding benzyl bromides or chlorides. ${ }^{7-11}$

We chose $\mathrm{N}$-fluorobenzenesulfonimide (NFBS) ${ }^{4}$ as fluorinating agent and hexachloroethane as chlorinating agent because they are stable, crystalline, easy to handle and commercially available reagents. Moreover, the by-product of chlorination is volatile and easy to eliminate.

The diethyl benzylphosphonates $\mathbf{1}$ are first deprotonated with lithium hexamethyldisilazane (LiHMDS) 3.3 eq. at low temperature to give stable benzylic anions which are reacted at room temperature with $\mathrm{Me}_{3} \mathrm{SiCl}$ (TMSCl) to afford quantitatively silylated benzylic anions 2 ( $\left.\delta{ }^{31} \mathrm{P}(\mathrm{THF})=+45-47 \mathrm{ppm}\right)$. At low temperature, the resulting carbanions 2 undergo halogenation reaction to give the protected diethyl $\alpha$ fluoro- $\mathbf{3}$ and $\alpha$-chloro- $\mathbf{4}$ benzylphosphonates which, after deprotection, produce the desired fluorinated $\mathbf{5}$ a-f and chlorinated 6 a-f materials (Scheme 1). To explore the scope and applicability of this method, the synthesis was monitored by ${ }^{31} \mathrm{P}-\mathrm{NMR}$ spectrometry.

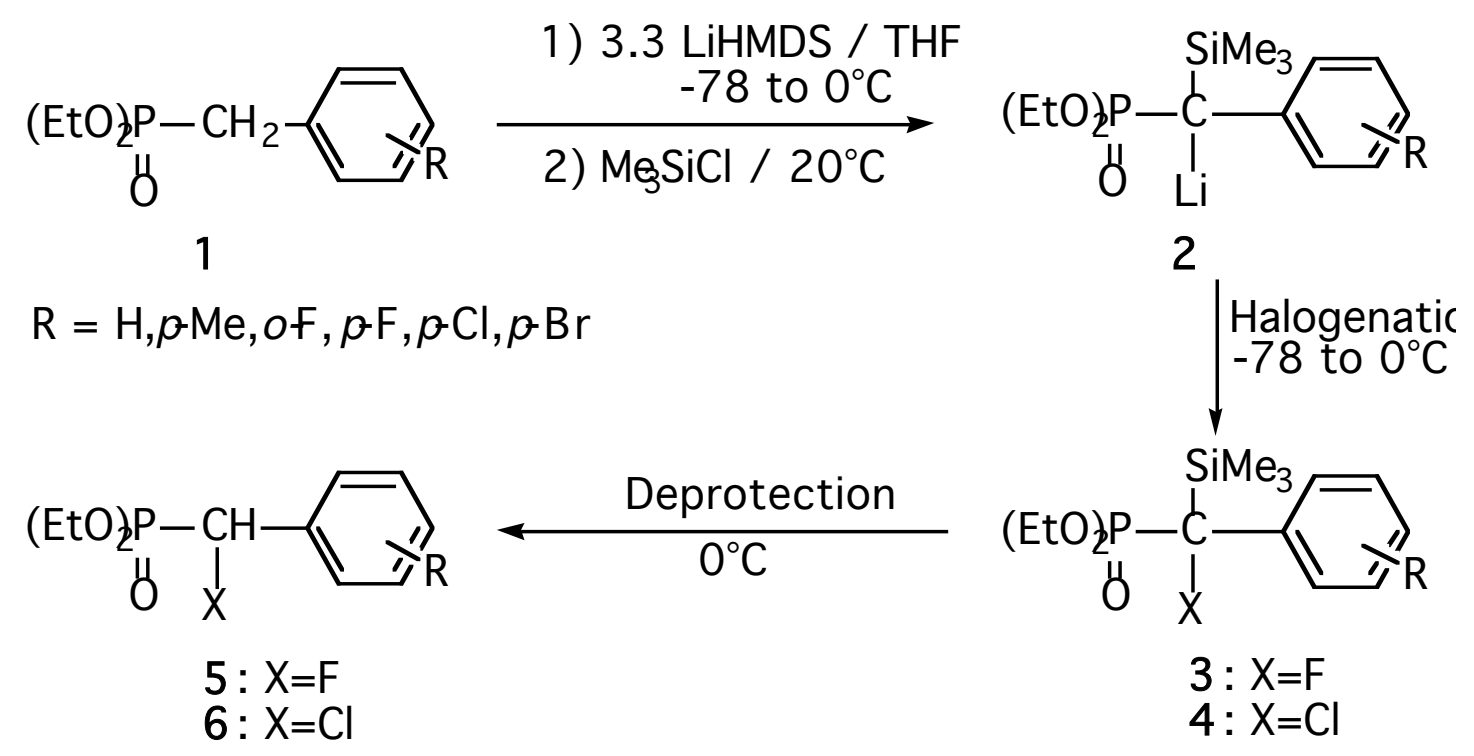

\section{Scheme 1}

We chose LiHMDS as base because HMDS, after regeneration in the reaction medium, is compatible with $\mathrm{TMSCl}$ even at room temperature, whereas both diisopropylamine and tetramethylpiperidine react with TMSCl, generating a chlorhydrate able to protonate the carbanions 2.

We observed that silylation takes place completely only at room temperature with 1.1 eq. of TMSCl. The use of an excess of TMSCl has a detrimental effect since it reacts with NFBS inducing an halogen exchange. While the first deprotonation is a fast reaction at low temperature, it appears that the second is slow and for complete generation of $\mathbf{2}$ it is necessary to operate with an excess of LiHMDS (3.3 eq.). In these conditions, carbanions 2 are obtained quickly and cleanly at room temperature. The need for an excess of base was confirmed independently by metallation of diethyl $\alpha$-(trimethylsilyl)benzylphosphonate, which was achieved with at least 2 eq. of LiHMDS. This result confirms that the second deprotonation is slowed down by the low nucleophilicity and steric requirements of LiHMDS.

The halogenation with NFBS or hexachloroethane (1.2 eq.) is efficiently and rapidly carried out at $-78^{\circ} \mathrm{C}$ in THF. Thereafter, the reaction mixture is warmed up to room temperature. In the case of the chlorination, the resulting compounds $\mathbf{4}$ are treated in situ with an excess of EtOLi in anhydrous EtOH which effects the facile and clean removal of the trimethylsilyl group. We found that this methodology was not 
Table 1. Diethyl $\alpha$-fluorobenzylphosphonates 5

\begin{tabular}{|c|c|c|c|c|c|}
\hline 5 & $\begin{array}{l}\text { Rdt. } \\
(\%)\end{array}$ & $\begin{array}{c}\delta^{31} \mathrm{P}(\mathrm{ppm}) \\
\left(\mathrm{CDCl}_{3}\right)\end{array}$ & $\begin{array}{c}\delta_{\mathrm{CHF}}{ }^{19} \mathrm{~F} \\
(\mathrm{ppm})\left(\mathrm{CDCl}_{3}\right. \\
)\end{array}$ & $\delta_{{ }_{\mathrm{CHF}}{ }^{1} \mathrm{H}(\mathrm{ppm})}$ & $\begin{array}{c}\delta_{\underline{\mathrm{CHF}}}{ }^{13} \mathrm{C}(\mathrm{ppm}) \\
\left(\mathrm{CDCl}_{3}\right)\end{array}$ \\
\hline $\mathbf{a}$ & 97 & $\begin{array}{c}13.0(\mathrm{~d} \\
\left.2 J_{\mathrm{PF}}=85.6\right)\end{array}$ & $\begin{array}{l}-200.6(\mathrm{~d}, \\
\left.{ }^{2} J_{\mathrm{PF}}=85.6\right)\end{array}$ & $\begin{array}{c}5.75(\mathrm{dd}, \\
2 J_{\mathrm{PH}}=7.9, \\
\left.2 J_{\mathrm{FH}}=44.6\right)\end{array}$ & $\begin{array}{c}89.9(\mathrm{dd}, \\
1 J_{\mathrm{PC}}=170.5, \\
\left.1 J_{\mathrm{FC}}=184.2\right)\end{array}$ \\
\hline b & 90 & $\begin{array}{c}13.5(\mathrm{~d} \\
\left.2 J_{\mathrm{PF}}=87.7\right)\end{array}$ & $\begin{array}{l}-199.2(\mathrm{~d}, \\
\left.{ }^{2} J_{\mathrm{PF}}=86.9\right)\end{array}$ & $\begin{array}{c}5.70(\mathrm{dd}, \\
2 J_{\mathrm{PH}}=7.5, \\
\left.{ }^{2} J_{\mathrm{FH}}=44.4\right)\end{array}$ & $\begin{array}{c}89.6(\mathrm{dd}, \\
{ }^{1} J_{\mathrm{PC}}=172.4, \\
\left.{ }^{1} J_{\mathrm{FC}}=183.2\right)\end{array}$ \\
\hline c & 68 & $\begin{array}{c}12.9(\mathrm{~d} \\
\left.2 J_{\mathrm{PF}}=85.6\right)\end{array}$ & $\begin{array}{c}-199.2(\mathrm{~d}, \\
\left.{ }^{2} J_{\mathrm{PF}}=85.8\right)\end{array}$ & $\begin{array}{c}5.62(\mathrm{dd}, \\
2 J_{\mathrm{PH}}=7.5, \\
\left.{ }^{2} J_{\mathrm{FH}}=44.5\right)\end{array}$ & $\begin{array}{c}88.7(\mathrm{dd}, \\
{ }^{1} J_{\mathrm{PC}}=171.5, \\
\left.{ }^{1} J_{\mathrm{FC}}=183.9\right)\end{array}$ \\
\hline d & 74 & $\begin{array}{c}12.6(\mathrm{~d} \\
\left.2 J_{\mathrm{PF}}=83.3\right)\end{array}$ & $\begin{array}{c}-201.4(\mathrm{~d}, \\
\left.{ }^{2} J_{\mathrm{PF}}=83.6\right)\end{array}$ & $\begin{array}{c}5.70(\mathrm{dd}, \\
2 J_{\mathrm{PH}}=7.3, \\
\left.{ }^{2} J_{\mathrm{FH}}=44.5\right)\end{array}$ & $\begin{array}{c}88.9(\mathrm{dd}, \\
{ }^{1} J_{\mathrm{PC}}=172.9, \\
\left.{ }^{1} J_{\mathrm{FC}}=184.0\right)\end{array}$ \\
\hline $\mathbf{e}$ & 76 & $\begin{array}{c}14.4(\mathrm{~d} \\
\left.2 J_{\mathrm{PF}}=85.1\right)\end{array}$ & $\begin{array}{l}-199.7(\mathrm{~d}, \\
\left.{ }^{2} J_{\mathrm{PF}}=85.4\right)\end{array}$ & $\begin{array}{c}5.77(\mathrm{dd}, \\
{ }^{2} J_{\mathrm{PH}}=8.0, \\
\left.{ }^{2} J_{\mathrm{FH}}=44.6\right)\end{array}$ & $\begin{array}{c}89.1(\mathrm{dd}, \\
{ }^{1} J_{\mathrm{PC}}=171.0, \\
\left.{ }^{1} J_{\mathrm{FC}}=184.6\right)\end{array}$ \\
\hline f & 68 & $\begin{array}{c}12.6(\mathrm{dd}, \\
{ }^{2} J_{\mathrm{PF}}=88.6 \\
\left.{ }^{4} J_{\mathrm{PF}}=5.2\right)\end{array}$ & $\begin{array}{l}-204.0(\mathrm{~d}, \\
\left.{ }^{2} J_{\mathrm{PF}}=90.4\right)\end{array}$ & $\begin{array}{c}6.10(\mathrm{dd}, \\
{ }^{2} J_{\mathrm{PH}}=8.0, \\
\left.{ }^{2} J_{\mathrm{FH}}=44.2\right)\end{array}$ & $\begin{array}{c}83.5(\mathrm{ddd}, \\
{ }^{1} J_{\mathrm{PC}}=177.0, \\
{ }^{1} J_{\mathrm{FC}}=180.1, \\
\left.{ }^{3} J_{\mathrm{FC}}=3.0\right)\end{array}$ \\
\hline
\end{tabular}

Table 2. Diethyl $\alpha$-chlorobenzylphosphonates 6

\begin{tabular}{|c|c|c|c|c|}
\hline 6 & $\begin{array}{l}\text { Rdt. } \\
(\%)\end{array}$ & $\begin{array}{c}\delta^{31} \mathrm{P}(\mathrm{ppm}) \\
\left(\mathrm{CDCl}_{3}\right)\end{array}$ & $\begin{array}{c}\delta_{\mathrm{CHCl}}{ }^{1} \mathrm{H}(\mathrm{ppm}) \\
\left(\mathrm{CDCl}_{3}\right)\end{array}$ & $\begin{array}{c}\delta_{\underline{\mathrm{CHCl}}}{ }^{13} \mathrm{C}(\mathrm{ppm}) \\
\left(\mathrm{CDCl}_{3}\right)\end{array}$ \\
\hline $\mathbf{a}$ & 93 & $18.2(\mathrm{~s})$ & $4.87\left(\mathrm{~d},{ }^{2} \mathrm{~J}_{\mathrm{PH}}=14.1\right)$ & $53.2\left(\mathrm{~d},{ }^{1} \mathrm{~J}_{\mathrm{PC}}=159.6\right)$ \\
\hline $\mathbf{b}$ & 90 & $17.5(\mathrm{~s})$ & $4.90\left(\mathrm{~d},{ }^{2} \mathrm{~J}_{\mathrm{PH}}=13.9\right)$ & $53.3\left(\mathrm{~d},{ }^{1} \mathrm{~J}_{\mathrm{PC}}=161.2\right)$ \\
\hline c & 94 & $17.0(\mathrm{~s})$ & $4.75\left(\mathrm{~d},{ }^{2} \mathrm{~J}_{\mathrm{PH}}=14.1\right)$ & $53.1\left(\mathrm{~d},{ }^{1} \mathrm{~J}_{\mathrm{PC}}=160.6\right)$ \\
\hline d & 93 & $16.4(\mathrm{~s})$ & $4.79\left(\mathrm{~d},{ }^{2} \mathrm{~J}_{\mathrm{PH}}=14.3\right)$ & $53.3\left(\mathrm{~d},{ }^{1} \mathrm{~J}_{\mathrm{PC}}=160.2\right)$ \\
\hline $\mathbf{e}$ & 93 & $16.4(\mathrm{~s})$ & $4.75\left(\mathrm{~d},{ }^{2} \mathrm{~J}_{\mathrm{PH}}=14.3\right)$ & $53.1\left(\mathrm{~d},{ }^{1} \mathrm{~J}_{\mathrm{PC}}=159.5\right)$ \\
\hline $\mathbf{f}$ & 92 & $16.6(\mathrm{~s})$ & $5.20\left(\mathrm{~d},{ }^{2} \mathrm{~J}_{\mathrm{PH}}=14.3\right)$ & $45.0\left(\mathrm{~d},{ }^{1} \mathrm{~J}_{\mathrm{PC}}=163.3\right)$ \\
\hline
\end{tabular}


suited for the fluorinated derivatives 3 despite the total cleavage of the $\mathrm{C}$-Si bond, because the resulting $\mathrm{N}$ ethylbenzenesulfonimide is very difficult to separate from the desired products. Thus, we replaced this treatment by an hydrolysis with an aqueous solution of $\mathrm{LiOH} 1 \mathrm{M}$ which affords at the same time a smooth, immediate removal of the trimethylsilyl moiety and the best way to retain the benzenesulfonimide in the aqueous layer. Employment of $\mathrm{NaOH} 1 \mathrm{M}$ is however not so satisfying because the benzenesulfonimide is not completely retained in water in these conditions. After acidic work-up and extraction, the desired $\alpha$ halogenobenzylphosphonates 5 a-f and 6 a-f are isolated in good to excellent yields. Examination of the spectral data $\left({ }^{31} \mathrm{P},{ }^{19} \mathrm{~F},{ }^{1} \mathrm{H},{ }^{13} \mathrm{C}-\mathrm{RMN}\right)$ shows that further purifications (distillation or chromatography) are not necessary. A clear illustration of the advantages of this novel synthetic procedure is provided by some representative examples collected in Tables 1 and 2.

We are currently extending this methodology to the synthesis of $\alpha$-monobromo- and $\alpha$-monoiodobenzylphosphonates as well as heterocyclic analogs.

\section{Aknowledgements}

We are grateful to the CNRS and Ecole Polytechnique for financial support to B.I.

\section{References}

1. (a) Bergmann, E.D.; Shahak, I.; Appelbaum, J. Isr.J.Chem. 1968, 6, 73. (b) McCarthy, J.R.; Jarvi, E.T.; Matthews, M.L.; Prakash, N.J.; Bowlin, T.L.; Mehdi, S.; Sunkara, P.S.; Bey, P. J. Amer. Chem. Soc. 1989, 111, 1127. (c) Tsai, H.J. Tetrahedron Lett. 1996, 37, 629.

2. O'Hagan, D.; Rzepa, H. S. Chem. Comm. 1997, 7, 645.

3. (a) Zimmer, H.; Bercz, P.J.; Maltenieks, O.J.; Moore, M.W. J. Amer. Chem. Soc. 1965, 87, 2777.

(b) Gallagher, M.J.; Noerdin, H. Aust. J. Chem. 1985, 38, 997. (c) Kondo, K.; Ohnishi, N.; Takemoto, K.; Yoshida, H.; Yoshida, K. J.Org.Chem. 1992, 57, 1622.

4. (a) Differding, E.; Ofner, H. Synlett 1991, 187. (b) Differding, E.; Duthaler, R. O.; Kreiger, A.; Rüegg, G. M.; Schmit, C. Synlett 1991, 395.

5. (a) Taylor, S.D.; Dinaut, A.N.; Thadani, A. T.; Huang, Z. Tetrahedron Lett. 1996, 37, 8089. (b) Chen, W.; Flavin, M. T.; Filler, R.; Xu, Z.-Q. Tetrahedron Lett. 1996, 37, 8975. (c) Taylor, S.D.; Kotoris, C.C.; Dinaut, A.N.; Chen, M.-J. Tetrahedron 1998, 54, 1691. (d) Qiu, W.; Burton, D.J. Tetrahedron Lett. 1996, 37, 2745.

6. $\quad$ Burke Jr., T.R.; Ye, B.; Akamatsu, M.; Ford Jr., H.; Yan, X.; Kole, H. K.; Wolf, G.; Shoelson, S. E.; Roller, P. P. J. Med.Chem. 1996, 39, 1021.

7. (a) Saunders, B. C.; Stacey, G. J.; Wild, F.; Wilding, I. G. E. J. Chem. Soc. 1948, 699. (b) Gronowitz, S.; Stenhammar, K.; Svensson, L. Heterocycles 1981, 947. (c) Cabares, J.; MavoungouGomes, L. Bull. Soc. Chim. Fr.1986, 3, 401. (d) Mouysset, G.; Bellan, J.; Payard, M.; TisneVersailles, J.; Farmaco Ed. Sci. 1987, 42, 805.

8. Williams, A.; Naylor, R. A.; Collyer, S. G. J. Chem. Soc., Perkin Trans. 2 1973, 25.

9. Brettle, R.; Dunmur, D. A.; Hindley, N. J.; Marson, C. M. J. Chem. Soc., Chem. Commun. 1992, 410.

10. Nasser, J.; About-Jaudet, E.; Collignon, N. Phosphorus, Sulfur Silicon Relat. Elem. 1990, 54, 171. 
11. (a) Savignac, P.; Lavielle,G. Bull. Soc. Chim. Fr. 1974, 1506. (b) Kennedy, G.; Perboni, A. D.; Tetrahedron Lett. 1996, 37, 7611. 